\title{
Brain Damages by Tripanossoma cruzi Increased Blood Brain Barrier Permeability in Holtzman Rats: Blood Brain Barrier Permeability in Chagas' Disease
}

\author{
João Roberto da Mata ${ }^{1}$, Fabiana Ribeiro da Mata $^{1}$, Hisao Nishijo ${ }^{2}$ and Tales Alexandre Aversi-Ferreira ${ }^{*}, 2,3$ \\ ${ }^{I}$ Department of Anatomy, Institute of Biological Sciences, Federal University of Goias, Goiânia, Goiás, Brazil \\ ${ }^{2}$ System Emotional Science, Graduate School of Medicine and Pharmaceutical Sciences, University of Toyama, Toyama, \\ Japan \\ ${ }^{3}$ Laboratory of Biochemistry and Neurosciences (Labine), Department of Nursing, Institute of Biological Sciences (ICB), \\ Federal University of Goiás, Brazil
}

\begin{abstract}
The T. cruzi strains are a complex of multi-clonal populations that affects the brain with more severity in children or young animals, suggesting that functional immaturity of the blood brain barrier (BBB) might be involved in $T$. cruzi infection in the brain. This study investigated relationships between BBB permeability and $T$. cruzi infection in the rat brain. The animals were inoculated with one of 3 strains of $T$. cruzi at 30 days of age, and BBB permeability was increased by subcutaneous kainic acid injection in half of the infected animals. The animals were sacrificed at 13 days of infection. The brain sections were stained with hematoxylin and eosin. The all brains of the infected animals with and without kainic acid showed both glial nodules and perivascular infiltrates due to T. cruzi infection. Number of these glial nodules was counted in each rat, and statistical comparison indicated that kainic acid-treatment significantly increased mean numbers of glial nodules in all of the rats infected with the 3 strains. The results indicated that the increased BBB permeability was one of the factors for facilitation of the entry of $T$. cruzi into the brain.
\end{abstract}

Keywords: Trypanosoma cruzi, blood brain barrier, kainic acid and brain.

\section{INTRODUCTION}

Chagas disease is a protozoal disease with high incidence in Brazil and Latin America, but it also occurs in Central America and southern United States [1]; however, it is regarded as a neglected disease that affects five to eight million individuals in Brazil [2-4] and about 7\% of the population in Latin America. It is estimated that carriers of the disease are about $25 \%$ of the population, which can generate a high probability of contamination $[5,6]$.

The Chagas disease morbidity is related, at least in part, to factors dependent on the parasite that influence its tropism for different organs $\lceil 2,7,8\rceil$ and an important target of $T$. cruzi is the central neural system (CNS) [9], which is involved in approximately $10 \%$ of cases [10]. This disease is more severe in children under two years of age [2] and young rats' immunosuppressed by gamma irradiation [2, 11], individuals under immunosuppression affected by acquired immunodeficiency syndrome (AIDS), lymphoreticular malignancies or heart, kidney and bone marrow transplants [1].

In adult experimental animals, infection with $T$. Cruzi in the CNS is more resistant compared to other organs [7, 12,

*Address correspondence to this author at the System Emotional Science, Graduate School of Medicine and Pharmaceutical Sciences University of Toyama 2630 Sugitani, Toyama 930-0194, Japan; Tel: +81 076434 7216; Fax:+81076 434 5012; E-mails: aversiferreira@gmail.com, tales@med.utoyama.ac.jp
13]; however, it is more serious in young animals, putatively due to changes in the functional state of the blood brain barrier (BBB) [14, 15], as proposed by Mata and colleagues [2] for Chaga's disease encephalitis. These results suggest that the BBB is one of the protective mechanisms against $T$. cruzi infection. Although the entry mechanism of several infectious agents in the CNS is not completely understood $[2,14]$, advancing age seems to provide a relative protection to the brain of children against infections such as meningitis and bacterial encephalitis.

Understanding of the molecular processes associated with proteins with specific functions in cells such as those in the BBB is important to elucidate the etiology and pathogenesis of neurological diseases [18]. Most resistance acquired with increasing age seems to depend, at least in part, on changes in receptors associated with the BBB [16] with marked decreased number of gap junctions [9] that provide, in part, the property of BBB occlusion [17]. Therefore, $\mathrm{BBB}$ disturbance might modulate various pathological changes in the brain due to infection. An increase in BBB permeability occurs during the course of some diseases such as infection by Trypanosoma brucei brucei [16], AIDS, multiple sclerosis, stroke, meningitis, and Alzheimer's disease $[2,10,14]$, some of which might make $T$. cruzi infection in the CNS more severe. An aggravating factor associated with BBB in the Chaga's disease is that glial cells, particularly astrocytes, have higher parasitemia, while neurons are rarely attacked [1]. Since astrocytes are considered as the basis for the development of endothelial cells in the brain, which are the main cellular elements of the BBB 
[19], astrocyte infection might induce BBB damages. In the present study, we hypothesized that $T$. cruzi infection in the CNS is modulated by BBB permeability.

However, the T. cruzi strains are a complex of multiclonal populations different in morphology, genetic and biochemistry characteristics and behavior in vertebrate host [21]. Mata and colleagues [2,14] reported that the involvement of the brain BBB in rats infected with $T$. cruzi differs among the previous studies, which might be ascribed to the different tropisms (parasite-host relations) of the different strains of this parasite in the CNS. Therefore, the hypothesis of the action of BBB on the $T$. cruzi access to the brain remains to be unconclusive. In the present study, we assessed pathogenesis of $T$. cruzi of different strains in the brain of rats submitted to alterations in the BBB permeability by kainic acid. Kainic acid is reported to increase BBB permeability [20].

\section{MATERIAL AND METHODS}

The entire procedure was approved by the Ethics Research Committee of the Federal University of Minas Gerais, which is part of the "Chagas Disease" project from the Laboratory of Neurobiology at the Institute of Biological Sciences, Federal University of Minas Gerais (UFMG), also following standards of the "Brazilian College of Animal Experimentation" (COBEA) and the Food and Drug Administration (FDA).

A total of 72 Holtzman rats were infected at 30 days of age with Y [22], PNM [23] or CL-Brener clone strains [23] of $T$. cruzi, all of which were derived from mice and other kinds of laboratory animals [24]. Groups were composed of six animals each, which were kept at the vivarium of the UFMG Laboratory of Biochemistry and Neuroscience throughout the experiment, receiving water and food (Labina / purina) ad libitum.

The animals were divided into 8 groups (Table 1). Some animals were treated with kainic acid (Aldrich Chemical Company) to increase the BBB permeability. The kainic acid was administered at a dose of $6 \mathrm{mg}$ subcutaneously [25, 26], and $T$. cruzi was inoculated immediately after kainic acid treatment. The inoculum of $5 \times 10^{3}$ trypomastigotes / $50 \mathrm{~g}$ of animal of Y, PNM, and CL-Brener clone strains of the $T$. cruzi were used. The animals were sacrificed 13 days after being infected.
The animals were sacrificed under anesthesia with chloral hydrate (Reagen), perfused with 4\% paraformaldehyde, and care was taken to avoid suffering to animals. The brain was removed from the cranium and sectioned in the frontal plane at three levels: 1) optic chiasm, 2) pituitary infundibulum, 3) middle portion of the pons, and three blocks (first block anterior to the optic chiasm, second block between the optic chiasm and pituitary infundibulum, and third block between the pituitary infundibulum and middle portion of the pons) were further processed for histological analysis.

The three brain blocks were post-fixed with 4\% paraformaldehyde in $0.1 \mathrm{M}$ phosphate buffer $\mathrm{pH} 7.2$, dehydrated in ethanol, diaphanized in xylene and embedded in Paraffin. The brain blocks were then sectioned in $5 \mu \mathrm{m}$ thickness and stained with hematoxylin and eosin. Counting of glial nodules was done throughout 8 sections per rat (each 3 sections from the first and second blocks and 2 sections from the third block) at a final magnification of $\mathrm{x} 100$ and the numbers of glial nodules were expressed per $\mathrm{cm}^{2}$. The data were analyzed using the BioStat 2009 Professional software.

Changes in BBB permeability induced by kainic acid were verified using another groups of the rats (30 days of age) $(n=8)$. Four rats were similarly inoculated and received kainic acid injection. Then, $0.2 \mathrm{ml}$ of Evans Blue solution (2\%) was administered from the posterior vena cava $3 \mathrm{hr}$ after kainic acid administration [27, 28]. The remaining 4 rats received Evans blue injection $3 \mathrm{hr}$ after inoculation.

\section{RESULTS}

Forty minutes after kainic acid administration, the animals showed symptoms consistent with Lassmann et al. [20] such as salivation, excessive lacrimation, hair raised, tendency to rely on their hind legs, nose and mouth bleeding, tremors, restlessness, aggressiveness, increased respiratory rate and prostration.

The administration of Evans blue provided increased BBB permeability $3 \mathrm{hr}$ after kainic acid administration in the animals infected with $T$. cruzi (left panel in Fig. 1A). However, a leakage of the dye from the BBB was less in the animals without treatment of kainic acid (right panel in Fig. 1A). It is noted that a dye leakage was stronger in the gray matter than the white matter in both the infected animals with and without kainic acid treatment.

Table 1. Relationships between the Types of Analysis, Strains Studied, Numbers of Animals and the Number of Groups

\begin{tabular}{|c|c|c|c|c|c|}
\hline Types of Analysis & $\begin{array}{l}\text { Number of Animals } \\
\text { for Y Strain }\end{array}$ & $\begin{array}{l}\text { Number of Animals } \\
\text { for PNM Strain }\end{array}$ & $\begin{array}{l}\text { Number of Animals for } \\
\text { CL-Brener Strain }\end{array}$ & $\begin{array}{l}\text { Number of } \\
\text { Groups }\end{array}$ & $\begin{array}{c}\text { Number of } \\
\text { Animals }\end{array}$ \\
\hline Rats with no treatment & - & - & - & 1 & 18 \\
\hline Rats treated only with kainic acid & - & - & - & 1 & 18 \\
\hline Rats inoculated only with one strain & 6 & 6 & 6 & 3 & 18 \\
\hline $\begin{array}{l}\text { Rats treated with kainic acid and } \\
\text { inoculated with one strain }\end{array}$ & 6 & 6 & 6 & 3 & 18 \\
\hline Total & & & & & 72 \\
\hline
\end{tabular}



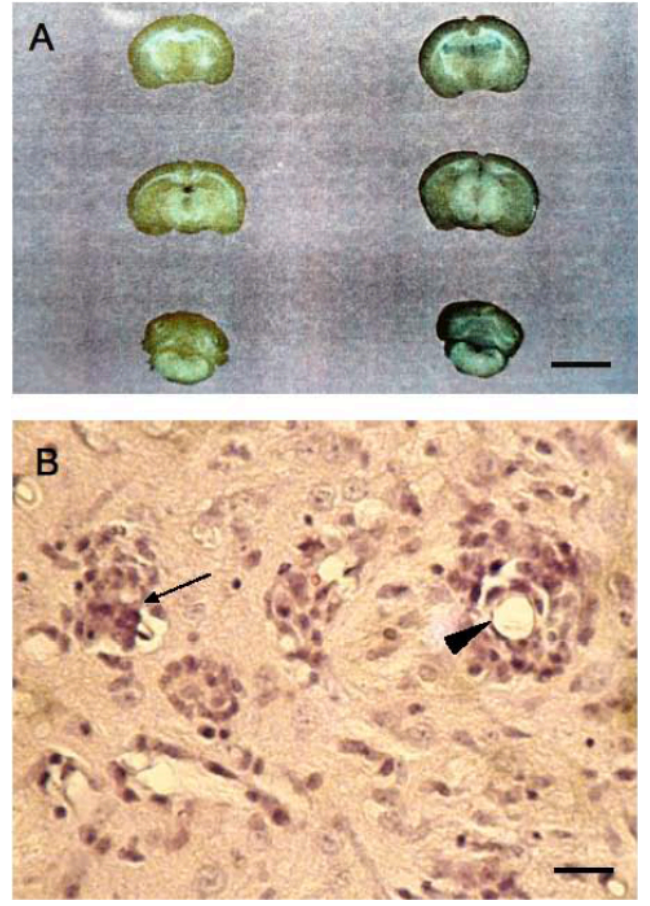

Fig. (1). Brains of the rats at 30 (A) and 43 (B) days age. A. Submitted to intravascular administration of 2\% Evans blue. The control brain (the left panels) with infection but without treatment of kainic acid showed a few penetration of the dye. The kainic acidtreated samples (the right panels) with infection showed stronger blue color [scale bar $=0.9 \mathrm{~cm}$ ]. The animals were sacrificed $3 \mathrm{hr}$ after administration of kainic acid or inoculation. B. Glial nodule (arrow) and perivascular infiltrate (arrowhead) in the cerebral cortex of the rat 43 days old inoculated with $T$. cruzi. The animals were sacrificed on day 13 after infection [hematoxylin and eosin, scale bar $=20 \mu \mathrm{m}]$.

Fig. (1B) shows a photomicrograph of glial nodules and perivascular infiltrates in the kainic acid-treated animals with infection indicating brain damages. The all brains of the infected animals with and without kainic acid showed both glial nodules and perivascular infiltrates. Statistical comparison by one-way analysis of variance (ANOVA) indicated that there was a significant difference in number of glial nodules among the 6 groups with infection with and without kainic acid treatment $[\mathrm{F}(5,30)=45.97, \mathrm{p}<0.0001]$. Post-hoc tests (Newman-Keuls multiple comparison test) indicated that kainic acid-treatment significantly increased mean numbers of glial nodules in all of the 3 strain infection (Fig. 2). Furthermore, most inflammatory processes were observed in the gray matter. It is noted that the animals without infection (with and without kainic acid treatment) displayed no glial nodule (data not shown).

\section{DISCUSSION}

Symptoms resultant from the administration of kainic acid associated with the mortality rate of animals in the present study indicate its effectiveness, since the use of 10 to $12 \mathrm{mg} / \mathrm{kg}$ kainic acid in rats induces brain lesions with some deaths [7-27]. As shown in Fig. (1A), kainic acid clearly increased BBB permeability in the brains with T. cruzi infection.

In the present study, consistent with Mata et al. [14], inflammatory processes (i.e., glial nodules) were observed in the rat brains with $T$. cruzi infection, but not in the rat brains without infection. These inflammatory processes are different from those induced only by kainic acid in which number of gap junctions was decreased in the BBB [9, 16]. Kainic acid induced only perivascular infiltrates due to capillary collapse [20]. Therefore, an increase in this inflammatory process in the rat brain with infection by kainic acid treatment was ascribed to the entry of $T$. cruzi into the brain, not just to an increase in BBB permeability by kainic acid.

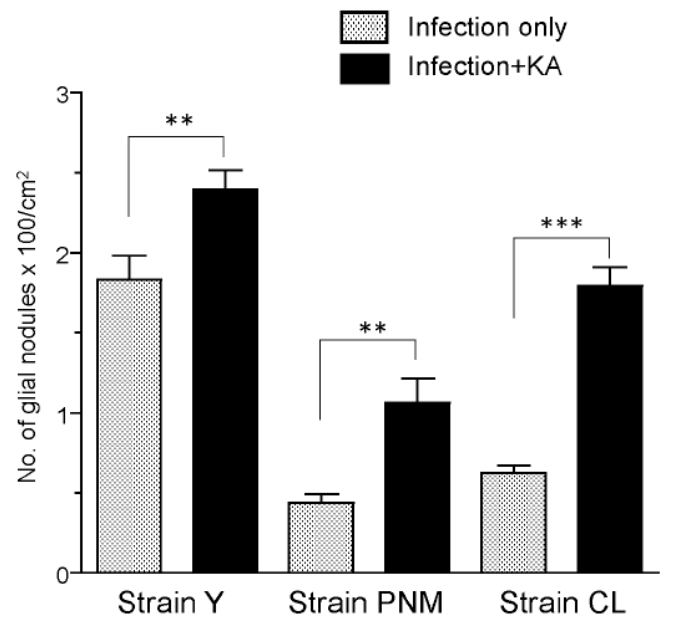

Fig. (2). Effect of the administration of kainic acid on the number of glial nodules $\left(\mathrm{x} 100 / \mathrm{cm}^{2}\right)$ in the brain of rats infected with $T$. cruzi at 30 days of age and sacrificed on day 13 after infection. **, $* * *$ : Significant difference at $\mathrm{p}<0.001$ and 0.0001 , respectively. The data are shown as mean \pm SE.

Thus, the increased BBB permeability induced by kainic acid was one of the factors for facilitation of the entry of $T$. cruzi into the brain, similar to what occurred with the more severe infection with Trypanosoma brucei (sleeping sickness) in rats $[15,23]$. Furthermore, inflammatory processes were more frequently observed in the gray matter where dye leakages from the BBB were stronger. Consistent with these results, previous studies suggested that increased BBB permeability is a facilitating factor for the infection in the CNS; patients who have other types of diseases that affect the $\mathrm{BBB}$ display the high prevalence of parasitemia in the brain $[1,2,10,11,14,16,20]$.

However, the way in which $T$. cruzi travels from the blood into the CNS is not completely understood. Other molecules may be involved in this process, since the acute phase of $T$. cruzi infection in rats is associated with high tumor necrosis factor levels (TNF) [29, 30], nitric oxide (NO) $[31,32]$ and macromolecules related to immune metabolisms [32].

Furthermore, the BBB plays a regulatory role in molecular exchanges between blood and CNS and is affected by gastrointestinal hormones such as insulin that controls the transport of amino acids and drugs, and other gastrointestinal 
hormones stimulate the $\mathrm{BBB}$ to release factors that control appetite [33]. Therefore, this systemic relationship of the BBB makes the analysis of factors that determine the penetration of $T$. cruzi somewhat complex and multivariate. For example, brain endothelial cells and astrocytes may be vulnerable to kainic acid, which would alter the expression of molecules associated with infection of $T$. cruzi in the CNS.

\section{CONCLUSIONS}

In conclusion, kainic acid affected the BBB permeability, possibly by decreasing the number of gap junctions, and increased the inflammatory processes. These results are consistent with the clinical findings that patients with diseases altering the $\mathrm{BBB}$ permeability have higher infection ratio in the CNS. However, there is evidence that the BBB permeability is associated with complex and multivariate systemic factors such as general changes in the health of animals and in the gastrointestinal tract. Further studies are required to elucidate infectious processes in the CNS.

\section{ACKNOWLEDGEMENTS}

This work was supported partly by CREST (Core Research for Evolutional Science and Technology), JST (Japan Science and Technology Agency), Japan, JSPS (Japan Society for the Promotion of Science) Asian Core Program, and the Ministry of Education, Science, Sports and Culture, Grant-in-Aid for Scientific Research (A) (22240051); and by CNPq (National Council of Technology and Development - Brazil). The funders had no role in study design, data collection and analysis, decision to publish, or preparation of the manuscript.

\section{CONFLICT OF INTEREST}

None declared.

\section{REFERENCES}

[1] Ferreira MS, Borges AS. Some aspects of protozoan infections in immunocompromised patients - a review. Mem Inst Oswaldo Cruz 2002; 94: 443-57.

[2] Mata JRM, Mata FR, Nascimento GNL, Aversi-Ferreira TA. Pequeno Comprometimento do encefalo em ratos Holtzman imunossuprimidos e infectados por Trypanossoma cruzi. Acta Sci Health Sci 2009; 31: 45-50.

[3] Oliveira AWS, Silva IG. Distribuição geográfica e indicadores entomológicos de triatomíneos sinantrópicos capturados no Estado de Goiás. Rev Soc Bras Med Trop 2007; 40: 204-8.

[4] Crema E, Madureira AB, Lima VGF, Castro AMW, Silva AA, Junqueira IS. Estudo da microflora do megaesôfago chagásico. Rev Soc Bras Med Trop 2002; 35: 39-42.

[5] Oliveira KM, Souza NB Jr, Mata, FR, Saboia-Morais SMT, AversiFerreira TA, Mata JRM. Alteracoes teciduais induzidas em ratos Wistar por Trypanossoma cruzi. Revista Eletrônica de Farmácia 2007; 4: 86-94.

[6] Carod-Artal FJ, Melo AP, Horan TA. American trypanosomiasis (Chaga's disease): unrecognized cause of stroke. J Neurol Neurosurg Psychiatr 2003; 74: 516-8.

[7] Melo RC, Brener Z. Tissue tropism of different Trypanosoma cruzi strains. J Parasitol 1978; 64: 475-82.
[8] WHO. Report of the steering committees research activities of the scientific working group (SWG) on Chagas`s disease. Mem Inst Oswaldo Cruz 1986; 8: 181-224.

[9] Campos Carvalho AC, Roy C, et al. Gap junction disappearance in astrocytes and leptomeningeal cells as a consequence of protozoan infection. Brain Res 1998; 790: 304-14.

[10] Prata A. Chagas' disease. Infect Dis Clin North Am 1994; 8: 61-76.

[11] Melo RCN, Machado CRS. Depletion of radiosensitive leukocites exarcebates the heart sympathetic denervation and parasitism in experimental Chaga's disease in rats. J Neuroimmunol 1998; 84: 151-7.

[12] Mata JR, Camargos ERS, Chiar E, Machado CRS. Tripanosoma cruzi infection and the rat central nervous system: proliferation of parasites in astrocytes and the brain reaction to parasitism. Brain Res Bull 2000; 46: 153-62.

[13] Costa SCG, Calabrese KS, Alencar AA, Lagrange PH Trypanosoma cruzi invasion on structures related to development and central nervous system. Rev Bras Neurol 1986; 22: 183-90.

[14] Mata FR, Souza MCR, Mata JR, Oliveira EC, Aversi-Ferreira TA. Alterações morfológicas do sistema nervosa central induzidas em camundongos por Trypanossoma cruzi. Acta Sci Health Sci 2008; 30: 41-5.

[15] Menezes H, Alcântara FG. Distribuição dos parasitas (pseudocistos) no sistema nervoso central de ratos infectados experimentalmente pelo Trypanosoma cruzi. Rev Goiana Med 1965; 11:21-5.

[16] Tuomanen E. Susceptibility to infection and age-related changes in the blood-brain barrier. Neurobiol Aging 1994; 15: 757-8.

[17] Bolton SJ, Anthony DC, Perry VH. Loss of the tigh junction proteins occluding and zonula occludens-1 from cerebral vascular endothelium during neutrophil-induced blood-brain barrier breakdown in vivo. Neuroscience 1998; 86: 1245-57.

[18] Ramos AT, Maiorka PC, Dagli MLZ, Graça DL. Gap junctions and communication within the nervous system. BJVP 2008; 1: 36-45.

[19] Abbott NJ. Astrocyte-endothelial interactions and blood-brain barrier permeability. J Anat 2002; 200: 629-38.

[20] Lassmann H, Petsche U, Kitz K, Baran H, Sperk G. The role of brain damage induced by systemic kainic acid injection. Neuroscience 1984; 13: 691-704.

[21] Andrade SG, Magalhães JB. Biodemes and zymodemes of Trypanosoma cruzi strains. Rev Soc Bras Med Trop 1997; 18: 2735.

[22] Silva AA, Nussenzweig G. Sobre uma cepa de Trypanosoma cruzi altamente virulenta para o camundongo branco. Folia Biol 1953; 20: 191-207.

[23] Brener Z, Chiari E. Variações morfológicas observadas em diferentes amostras de Trypanosoma cruzi. Rev Inst Med Trop São Paulo 1963; 5: 220-4.

[24] Sousa MA. Morphological characterization of Trypanosoma cruzi Chagas, 1909 and its distinction from other trypanosomes. Mem Inst Oswaldo Cruz 1999; 94: 205-10.

[25] Sperk G, Lassmann H, Baran H, Seitelberger F, Hornykiewicz O. Kainic acid-induced seizures: dose-relationships of behavioral, neurochemical and histophatological changes. Brain Res 1985; 338: 289-95

[26] Camargos ERS, Haertel LRM, Machado CRS. Preganglionic fibers of the adrenal medulla end cervical sympathetic ganglia: differential involvement during experimental American trypanosomiasis in rats. Int J Exp Pathol 1996; 7: 115-24.

[27] Petito CK, Schaefer JA, Plum F. Ultrastructural characteristics of the brain and blood-brain barrier in experimental seizures. Brain Res 1977; 127: 251-67.

[28] Steinwall RM, Klatzo I. Selective vulnerability of the blood-brain barrier in chemically induced lesions. J Neuroph Exp Neur 1966; 25: 542-99.

[29] Saija A, Princi P, Pisani A, et al. Blood-brain barrier dysfunctions following systemic injection of kainic acid seizures. Epilepsia 1984; 25: 255-68.

[30] Talerton RL, Tumor necrosis factor (cachectin) production during experimental Chaga's disease. Clin Exp Immunol 1988; 73: 186-90.

[31] Freire-de-Lima CG, Nascimento DO, Soares MPB, et al. Uptake of apoptotic cells drives the growth of a pathogenic trypanosome in macrophages. Nature 2000; 403: 199-203. 
[32] Pavaneli WR, Silva JN. The role of nitric oxide in immune response against Trypanosoma cruzi infection. Open Nitric Oxide J 2010: $2: 1-6$
[33] Banks WA. The blood-brain barrier: connecting gut and the brain. Regul Pept 2008; 149: 11-4.

Received: August 29, 2011

Revised: October 2, 2011

Accepted: October 15, 2011

(C) da Mata et al.; Licensee Bentham Open.

This is an open access article licensed under the terms of the Creative Commons Attribution Non-Commercial License (http://creativecommons.org/licenses/bync/3.0/), which permits unrestricted, non-commercial use, distribution and reproduction in any medium, provided the work is properly cited. 